Revista Destaques Acadêmicos, Lajeado, v. 12, n. 4, 2020. ISSN 2176-3070

DOI: http://dx.doi.org/10.22410/issn.2176-3070.v12i4a2020.2404

http://www.univates.br/revistas

\title{
UM OLHAR SOBRE A RECENTE PRODUÇÃO HABITACIONAL DE INTERESSE SOCIAL EM LAJEADO-RS
}

\author{
Tainá Manfredini ${ }^{1}$, Alice Rauber Gonçalves ${ }^{2}$
}

Resumo: A produção habitacional de interesse social tem se intensificado desde a criação do Programa Minha Casa Minha Vida (PMCMV), com a construção de moradias em larga escala. A implantação de empreendimentos habitacionais afeta desde a urbanização da cidade até a qualidade de vida dos moradores. O presente estudo discute a inserção urbana dos empreendimentos do PMCMV, investigando a recente produção habitacional de interesse social produzida no município de Lajeado - RS, por meio da análise de uma amostra de empreendimentos habitacionais. A análise conta com o auxílio da Ferramenta de Avaliação elaborada pelo Instituto de Políticas de Transporte e Desenvolvimento (ITDP) e possibilita a identificação de quais elementos impactam na qualidade da inserção urbana e da moradia. Os resultados obtidos apontam relação entre o padrão de urbanização do município e os problemas identificados nos empreendimentos habitacionais. A principal contribuição do trabalho está em evidenciar, por meio de indicadores objetivos, os problemas decorrentes do modelo de urbanização atual, como, por exemplo, a precariedade ou total ausência de certas infraestruturas que dão suporte à moradia, como transporte público e passeios adequados.

Palavras-chave: Habitação de Interesse Social. Inserção Urbana. Programa Minha Casa Minha Vida.

\section{INTRODUÇÃO}

Ao longo dos últimos quinze anos, retomou-se no Brasil a produção massiva de habitação de interesse social. Esse processo teve início em 2003, com o começo da construção de uma política nacional de habitação, e intensificou-se a partir de 2009, com a criação do Programa Minha Casa Minha Vida - PMCMV (CARDOSO; ARAGÃO; ARAUJO, 2011). Apesar de haverem programas operados pelos governos estaduais e municipais, a maior parte da

1 Graduada em Arquitetura e Urbanismo pela Universidade do Vale do Taquari - UNIVATES.

2 Doutoranda em Planejamento Urbano e Regional na Universidade Federal do Rio Grande do Sul - UFRGS. 
produção tem ocorrido no âmbito do PMCMV. Estudos apontam redução do déficit habitacional no período entre 2007 e 2012 (NETO; FURTADO; KRAUSE, 2013), porém é necessário constatar que essa produção tem sido acompanhada de diversos problemas, muitos dos quais relacionados à questão da inserção urbana.

Lajeado/RS, assim como diversas cidades no país todo, se insere nessa lógica contemporânea de produção habitacional de mercado, por meio do Programa Minha Casa Minha Vida, apresentando problemas semelhantes. Assim, o presente artigo busca trazer uma visão crítica sobre essa produção recente, tendo como enfoque a localização e inserção dos empreendimentos do Programa MCMV nesse município.

Buscando compreender como os empreendimentos MCMV estão sendo implantados em Lajeado, selecionou-se uma amostra de empreendimentos localizados em diferentes bairros da cidade, para os quais foram aplicados os critérios de análise da Ferramenta de Avaliação elaborada pelo Institute for Transportation and Develolpment Policy (ITDP). Os resultados, que mostram uma forte reprovação quanto à inserção dos empreendimentos, permitem uma discussão mais ampla sobre o contexto do município de Lajeado e seus padrões de urbanização.

\section{POLÍTICAS HABITACIONAIS E O PROGRAMA MINHA CASA MINHA VIDA}

O enfrentamento do déficit habitacional, no Brasil, se caracteriza historicamente pela ausência de políticas públicas, em alguns períodos, e por mecanismos insuficientes em outros (BONDUKI, 1994, 2008). Uma das principais iniciativas no século $X X$ foi a criação do Sistema Financeiro de Habitação (SFH) e Banco Nacional de Habitação (BNH), criados nos anos 1960 para responder ao agravamento da crise habitacional ocasionada pelo processo migratório do campo para as cidades (BONDUKI, 2008). Nos seus 22 anos de atuação, o BNH fortaleceu o setor da construção civil, financiando 4,3 milhões de moradias, mas excluiu parcelas importantes da população de baixa renda (BONDUKI, 2008). A produção desse período também é bastante criticada no que se refere à inserção urbana dos conjuntos habitacionais (LIMA, 2016).

No período entre 1986 e 2003, isto é, entre o fim do BNH e a criação do Ministério das Cidades, ocorre um esvaziamento das políticas habitacionais e contata-se baixa produção de moradia (BONDUKI, 2008). Em 2003, o Ministério das Cidades começa a estruturar uma política nacional de habitação de interesse social consistente, porém a crise econômica de 2008 acaba levando o governo a criar um programa não apenas voltado para o combate ao déficit, mas também para impulsionar a economia através do setor da construção civil (CARDOSO; ARAGÃO; ARAÚJO, 2011). Assim, em 2009 é lançado o Programa Minha Casa Minha Vida (PMCMV). Originalmente se dividia em 3 faixas de 
financiamento, conforme o rendimento familiar mensal, sendo elas: Faixa 1 (de 0 a 3 salários mínimos); Faixa 2 (de 3 a 6 salários mínimos) e Faixa 3 (de 6 a 10 salários mínimos), com isso atendendo não só a demanda por habitação social (até 5 salários), mas também de outras faixas de renda. Em 2016 também foi criada a faixa 1,5, com condições intermediárias entre a faixas 1 e 2 .

Entre 2009 e 2019, 5.582.626 unidades habitacionais foram contratadas e 4.096.725 concluídas (BRASIL, 2019), o que demostra que o PMCMV finalmente retoma a produção de moradia em larga escala. No entanto, existem diversas críticas sobre a inserção urbana e a qualidade das unidades habitacionais construídas (LINKE et al, 2016; ANDRADE, DEMARTINI; CRUZ, 2014). Constata-se que os problemas do $\mathrm{BNH}$ se repetem, especialmente a construção de imensos conjuntos habitacionais na periferia, perpetuando o mesmo modelo de segregação (SILVA; TOURINHO, 2015).

De acordo com Vannuchi et al (2015), logo no início do PMCMV foram estabelecidas exigências de localização e parâmetros de implantação, com a edição da Medida Provisória $n^{\circ} 514$, de $1^{\circ}$ de dezembro de 2010. Embora essa medida tenha sido normatizada, na prática foi negligenciada, o PMCMV continua reforçando a segregação urbana. Conforme Andrade, Demartini e Cruz (2014, p. 54), "o preço baixo das terras distantes de centralidades e a cumplicidade de prefeituras mal-intencionadas ou menos estruturadas para legislar sobre o espaço urbano, favorecem ações perversas para a produção habitacional voltada para os pobres".

A limitação na escala dos empreendimentos, que seria de até 500 unidades, também é frequentemente burlada, pois muitos empreendedores agrupam diversos terrenos para ampliar a produção habitacional (CARDOSO; ARAGÃO; ARAÚJO, 2011; MELCHIORS, 2014). De acordo com Lima (2016) a produção em larga escala por meio da compra de terras distantes e com baixo custo colabora com a periferização e intensifica os problemas de vulnerabilidade e de segregação social.

Conforme Lima (2016), a segregação está diretamente relacionada com a implantação dos empreendimentos habitacionais, compreendendo a configuração e a localização. A localização adequada envolve: a distância entre o empreendimento habitacional e o centro urbano; a acessibilidade aos equipamentos urbanos; a acessibilidade à infraestrutura e aos locais de trabalho (LIMA, 2016). Cabe ressaltar que embora a questão da localização seja indispensável para a qualidade dos empreendimentos habitacionais, ela por si não garante a inserção urbana. Conforme Ferreira (2012), a qualidade da localização depende da adequada inserção na malha urbana, deve se evitar a formação de grandes áreas habitacionais sem mescla de usos, atividades e grupos sociais. A adequada inserção na malha urbana existente possibilita a fluidez urbana, por meio da harmonia entre o empreendimento habitacional e o entorno, evitando a implantação de barreiras físicas e visuais, como muros e grades. 
Em relação ao acesso de equipamentos e serviços, Lima (2011) comenta que o direito à moradia adequada envolve a disponibilidade de serviços, infraestrutura e equipamentos públicos. Porém, Freitas (2004) destaca que o acesso aos serviços e comércio fica comprometido em conjuntos habitacionais implantados em áreas distantes e isoladas. Além disso, o comércio e serviço local também encontra dificuldades para se estabelecer, pois nesse caso o público se restringe apenas aos próprios moradores dos conjuntos habitacionais.

Moysés et al (2013) aborda como problema recorrente da implantação dos empreendimentos habitacionais o impacto na mobilidade urbana. Os condomínios habitacionais distantes de equipamentos e serviços tornam necessária a extensão da rede de transportes até o condomínio habitacional, implicando em acréscimo de tempo e de custos para deslocamentos. Na maioria dos empreendimentos analisados por Linke et al (2016) a mudança para a nova moradia era acompanhada de um aumento nos custos de deslocamento dos moradores, assim como um aumento no uso do transporte motorizado. Ferreira (2012) também aponta que a má localização dos conjuntos habitacionais e a inexistência de transporte adequado favorece o modelo de cidade baseado no automóvel.

Vasta bibliografia na área de planejamento urbano já vem advogando por uma urbanização mais compacta (LEITE; AWAD, 2012) e a inserção de habitação de interesse social em áreas centrais (COMARU, 2012) ou pelo menos mais integradas às áreas dotadas de infraestrutura (LIMA, 2011; MINISTÉRIO DAS CIDADES; WRI, 2017). Comaru (2012) justifica que a localização privilegiada da moradia nas áreas centrais resulta em benefícios para os trabalhadores e suas famílias. Dentre os benefícios citados pelo autor estão: facilidade de acesso aos pontos de trabalho; acesso aos serviços públicos e sociais; e mais tempo para estudo e lazer. Além disso, Lima (2011) argumenta que um conjunto habitacional menor e inserido dentro da malha urbana da cidade, próximo de diversos usos necessários, com movimentação de pedestres e de veículos, contribui com a satisfação dos usuários dos empreendimentos habitacionais.

Deste modo, percebe-se que o PMCMV, ao promover um padrão de urbanização disperso e aumentar a segregação socioespacial, entra em divergência com as recomendações feitas por especialistas na área de planejamento urbano. De acordo com Rolnik e Nakano (2009) se não houverem estratégias adequadas para promover o acesso e a inserção urbana dos conjuntos habitacionais, o modelo habitacional periférico continuará a se reproduzir.

\section{O PMCMV EM LAJEADO}

O município de Lajeado, localizado na região do Vale do Taquari, no Rio Grande do sul, é considerado o polo da região. As últimas duas décadas foram marcadas por intenso crescimento populacional - os censos demográficos 
constatam que população passou de 64.133 habitantes, em 2000, para 71.445, em 2010, e atualmente estima-se que a população já ultrapasse os 84.000 habitantes (IBGE, 2019). Alguns empreendimentos do PMCMV se inserem nesse contexto de crescimento do município, com crescente demanda habitacional, e são analisados nesse artigo pelo ponto de vista de sua inserção urbana.

\subsection{Seleção e caracterização da amostra}

Para a análise foram selecionados 7 empreendimentos habitacionais do MCMV no município de Lajeado, sendo que 4 pertencem à faixa 1 ou 1,5 do programa, e 3 à faixa 2 ou 3. Todos foram lançados no período de 2010 a 2016 e se localizam em diferentes bairros da cidade, conforme pode ser observado na Figura 1 e na Tabela 1.

Observa-se que a maioria dos empreendimentos habitacionais se localizam em áreas mais periféricas, sendo que apenas o Residencial do Parque situa-se em uma região bem central, no bairro Centro, estando inserido dentro da malha urbana consolidada, em uma área com maior diversidade de usos. Em relação ao porte dos empreendimentos habitacionais, a maioria caracterizase por ser de porte médio, sendo que apenas o empreendimento Flores da Montanha é de porte pequeno, apresentando 64 unidades habitacionais. $\mathrm{O}$ maior, até o momento é o Novo Tempo I, localizado no bairro Santo Antônio. O conjunto habitacional possui 18 blocos com 16 apartamentos cada, totalizando 288 unidades habitacionais. Todos empreendimentos analisados são de tipologia multifamiliar, sob a forma de condomínios fechados. 
Figura 1-Empreendimentos habitacionais na cidade de Lajeado segundo as faixas de renda do programa

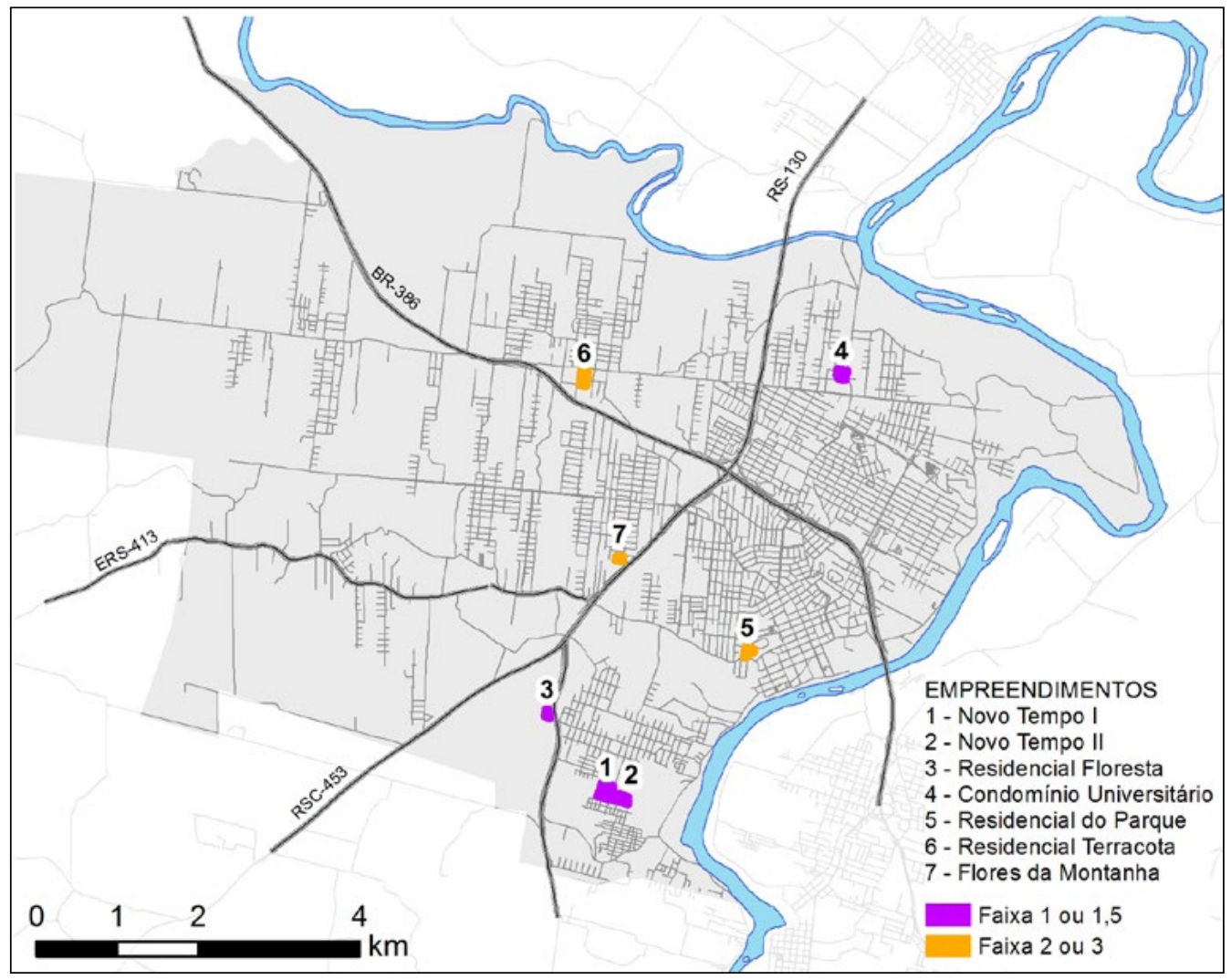

Fonte: Mapa elaborado pelas autoras por meio da ferramenta SIG

Tabela 1 - Informações gerais sobre os empreendimentos habitacionais

\begin{tabular}{|c|c|c|c|c|}
\hline EMPREENDIMENTO & BAIRRO & FAIXA & $\begin{array}{c}\text { N } \\
\text { HABITACIONADS }\end{array}$ & $\begin{array}{c}\text { ANO DE } \\
\text { LANÇAMENTO }\end{array}$ \\
\hline 1 - Novo Tempo I & Santo Antônio & 1 & 288 & 2016 \\
\hline 2 - Novo Tempo II & Santo Antônio & 1 & 160 & 2014 \\
\hline 3- Residencial Floresta & Floresta & 1 & 160 & 2010 \\
\hline $\begin{array}{c}\text { 4- Condomínio } \\
\text { Universitário }\end{array}$ & Universitário & 1,5 & 144 & 2016 \\
\hline 5 - Residencial do Parque & Centro & 02 ou 03 & 224 & 2014 \\
\hline 6- Residencial Terracota & Olarias & 02 ou 03 & 273 & - \\
\hline 7- Flores da Montanha & Montanha & 02 ou 03 & 64 & - \\
\hline
\end{tabular}

Fonte: Tabela elaborada pelas autoras 
Embora a amostra seja pequena em número de empreendimentos, ela é significativa pelo total de unidades habitacionais: 1.313 apartamentos. Considerando uma média de 3 moradores por domicílio, tal quantidade é capaz de abrigar quase 4.000 habitantes, que para a população de Lajeado é um número expressivo.

Além disso, estes empreendimentos representam a introdução de um novo padrão tipológico na cidade de Lajeado. A tipologia de condomínio fechado de médio ou grande porte praticamente inexistia pouco tempo atrás, conforme levantamento recente feito por Bergamaschi e Silveira (2014), que mostra predominância dos condomínios de pequeno porte - conhecidos como "sobrados". A tipologia dos empreendimentos MCMV impacta na relação entre o espaço público e privado.

\subsection{Metodologia}

Para análise dos empreendimentos habitacionais de Lajeado/RS foram aplicados os parâmetros a Ferramenta de Avaliação de Inserção Urbana desenvolvidos pelo Instituto de Políticas de Transporte e Desenvolvimento (ITDP, 2014). Tais parâmetros foram criados visando avaliar empreendimentos habitacionais faixa 1 do Programa Minha Casa Minha Vida, mas também servem como referência a projetos de empreendimentos habitacionais de maneira geral. Neste trabalho a ferramenta de avaliação do ITDP foi utilizada para avaliar empreendimentos habitacionais do programa MCMV de todas as faixas.

Os parâmetros de avaliação da inserção urbana definem critérios urbanísticos, sob a forma de indicadores, para avaliar projetos, aprovando-os ou rejeitando-os. Assim, a ferramenta do ITDP fornece subsídios para oportunizar espaços públicos com localização adequada, acesso ao transporte público e equipamentos, integração com o entorno, circulação confortável de pedestres e outras atividades de extrema importância. Os critérios da ferramenta são divididos em três temas, os quais estabelecem padrões mínimos de qualidade, são eles: transporte; oferta de equipamentos, comércio e serviços; desenho e integração urbana. No total são 9 indicadores, conforme Tabela 2, os quais fornecem parâmetros que permitem classificar os projetos em bom, aceitável ou insuficiente. 
Tabela 2 - Parâmetros Ferramenta de Avaliação de Inserção Urbana do ITDP

\begin{tabular}{|c|c|c|}
\hline TEMA & INDICADOR & CRITÉRIOS DE A VALIAÇÃO \\
\hline & 1 OPÇÕES DE TRANSPORTE & $\begin{array}{l}\text { * Considerar as paradas e estações } \\
\text { de transporte localizadas em um raio } \\
\text { de } 1 \mathrm{~km} \text { (distância percorrida a pé) } \\
\text { da entrada do edifício ou unidade } \\
\text { habitacional mais próxima ao centro } \\
\text { da poligonal do empreendimento. } \\
\text { * Identificar todas as linhas de } \\
\text { transporte que passam pelas paradas } \\
\text { e mapear seus itinerários. } \\
\text { * Verificar quantos itinerários } \\
\text { diferentes são possíveis a partir das } \\
\text { linhas válidas. }\end{array}$ \\
\hline 1 TRANSPORTE & $\begin{array}{l}2 \text { FREQUÊNCIA DO } \\
\text { TRANSPORTE }\end{array}$ & $\begin{array}{l}\text { * Conferir a frequência e o período de } \\
\text { operação em dias úteis das linhas de } \\
\text { transporte identificadas no Indicador } \\
1 \text {. Para isso considerar o período de } \\
\text { entrepico ( } 10 \mathrm{~h}-16 \mathrm{~h} \text { ) nos dias da } \\
\text { semana, caso não for possível, utilizar } \\
\text { o intervalo médio para o dia útil que } \\
\text { estiver disponível. } \\
\text { * Classificar a frequência: BOM (até } \\
10 \text { min - período de operação } 24 h \text { ); } \\
\text { ACEITÁVEL (11 a } 20 \text { min - período de } \\
\text { operação } 17 h) ; \text { INSUFICIENTE (acima } \\
\text { de } 20 \text { min - período de operação menos } \\
\text { de } 17 \mathrm{~h} \text { ). } \\
\text { * No caso de linhas com classificações } \\
\text { diferentes, prevalece a inferior. }\end{array}$ \\
\hline
\end{tabular}




\begin{tabular}{|c|c|c|}
\hline TEMA & INDICADOR & CRITÉRIOS DE A VALIAÇÃO \\
\hline \multirow{4}{*}{$\begin{array}{l}2 \text { OFERTA DE } \\
\text { EQUIPAMENTOS } \\
\text { COMÉRCIO E } \\
\text { SERVIÇOS }\end{array}$} & $\begin{array}{l}3 \text { USOS COTIDIANOS } \\
\text { * Obrigatórios: creches públicas; } \\
\text { Escolas públicas de Ensino } \\
\text { Infantil; áreas livres para lazer e } \\
\text { recreação; mercados, quitandas, } \\
\text { hortifrutis ou feiras. } \\
\text { * Complementares: açougues; } \\
\text { padarias; farmácias; restaurantes; } \\
\text { salão de beleza; academia; } \\
\text { lotéricas; assistência técnica e } \\
\text { reparação; lojas de material de } \\
\text { construção. }\end{array}$ & $\begin{array}{l}\text { * Identificar os Usos Obrigatórios } \\
\text { e Complementares que estejam } \\
\text { localizados em um raio de } 1 \mathrm{~km} \text { do } \\
\text { empreendimento. A distância a pé } \\
\text { do empreendimento até os diferentes } \\
\text { usos deve ser de no máximo } 1000 \mathrm{~m} \text {. } \\
\text { * Avaliar a capacidade de } \\
\text { atendimento da demanda, por } \\
\text { exemplo, se a creche tem vagas } \\
\text { suficientes para atender ao } \\
\text { empreendimento. } \\
\text { *Em relação aos Usos } \\
\text { Complementares: mais de um uso do } \\
\text { mesmo tipo deverá ser contabilizado } \\
\text { apenas uma vez. }\end{array}$ \\
\hline & 4 USOS EVENTUAIS & \\
\hline & $\begin{array}{l}\text { * Obrigatórios: Escolas públicas } \\
\text { de Ensino Fundamental; Escolas } \\
\text { públicas de Ensino Médio ou } \\
\text { Técnico; Unidades de saúde com } \\
\text { pronto atendimento; farmácias; } \\
\text { áreas para práticas esportivas; } \\
\text { supermercado; lotéricas ou caixas } \\
\text { eletrônicos. } \\
\text { * Complementares: Instituição } \\
\text { de Ensino Superior; Centro de } \\
\text { Referência de Assistência Social; } \\
\text { Biblioteca; Delegacia; Centro } \\
\text { médico ou clínicas especializadas; } \\
\text { Correios; loja de vestuários e } \\
\text { calçados e outros. }\end{array}$ & $\begin{array}{l}\text { * Localizar o Usos Obrigatórios e } \\
\text { Complementares e verificar se estão a } \\
\text { pelo menos } 1.400 \mathrm{~m} \text { de caminhada ou a } \\
30 \text { min utilizando transporte público. } \\
\text { *Avaliar a capacidade de atendimento } \\
\text { da demanda. } \\
\text { *Em relaçãoaos Usos Complementares: } \\
\text { mais de um uso do mesmo tipo deverá } \\
\text { ser contabilizado apenas uma vez. }\end{array}$ \\
\hline & $\begin{array}{l}5 \text { USOS ESPORÁDICOS } \\
\text { * Obrigatórios: Hospital público; } \\
\text { Centro público administrativo; } \\
\text { Instituição de Ensino Superior; } \\
\text { Bancos. } \\
\text { * Complementares: Cinemas; } \\
\text { Parque urbano, ginásio esportivo; } \\
\text { teatro; museu; hipermercado; } \\
\text { cartório. }\end{array}$ & $\begin{array}{l}\text { * Localizar os Usos Obrigatórios ou } \\
\text { Complementares, acessíveis em no } \\
\text { máximo } 1 \text { hora de deslocamento com } \\
\text { transporte público. } \\
\text { * Em relação aos Usos Obrigatórios: } \\
\text { avaliar a capacidade de atendimento } \\
\text { da demanda dos hospitais. } \\
\text { *Emrelaçãoaos Usos Complementares: } \\
\text { mais de um uso do mesmo tipo deverá } \\
\text { ser contabilizado apenas uma vez. }\end{array}$ \\
\hline
\end{tabular}




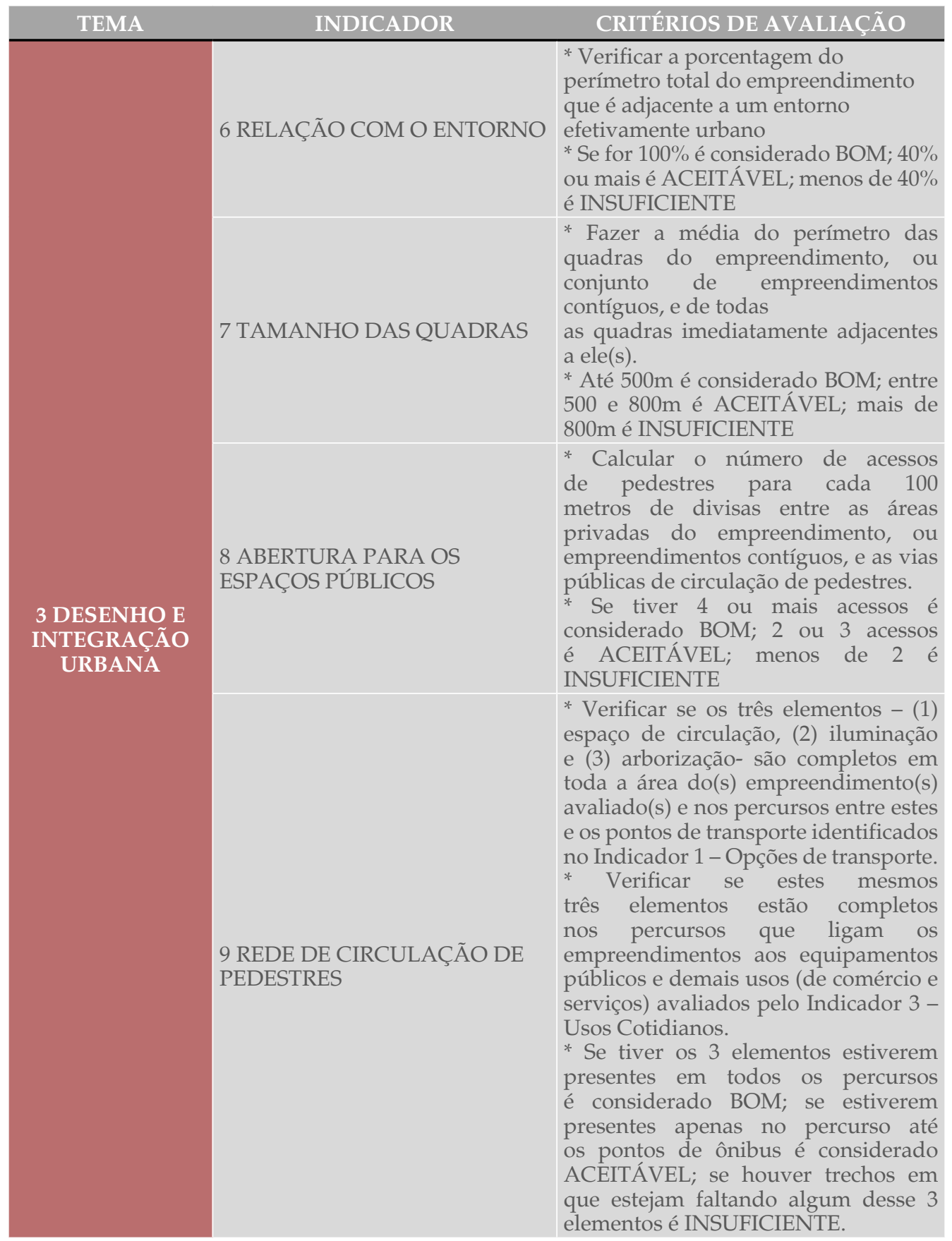

Fonte: Adaptado a partir da Ferramenta de Avaliação de Inserção Urbana (ITDP, 2018).

O primeiro tema, transporte, fornece parâmetros para a análise da relação do empreendimento com as opções de transporte público da cidade. Um bom resultado nessa categoria depende das opções de transporte existentes nas 
proximidades do empreendimento, dos itinerários, da quantidade de opções disponíveis e da frequência do transporte. O objetivo do tema transporte é garantir que os moradores dos empreendimentos habitacionais tenham acesso ao transporte público nas proximidades do empreendimento habitacional, diversidade de itinerários, frequência e tempo de espera adequado, para que assim os moradores consigam se deslocar de modo apropriado do empreendimento habitacional para os diferentes destinos da cidade.

Já o segundo tema busca verificar se há oferta de equipamentos, comércio e serviços próximos ao empreendimento habitacional e se a distância entre o empreendimento e os diversos usos é aceitável. Os usos compreendem uma lista de usos obrigatórios, que são necessários, e os usos complementares. Os indicadores destacam a importância da diversidade de usos cotidianos próximos ao empreendimento habitacional, de modo que os moradores consigam se deslocar a pé, por no máximo 15 minutos, para terem acesso aos usos cotidianos, como compras para abastecimento e deslocamentos diários com crianças pequenas. Já os usos eventuais podem ficar mais distantes do empreendimento, mas devem ser acessíveis com 20 minutos de deslocamento a pé ou 30 minutos de deslocamento por transporte público.

O terceiro tema tem como objetivo avaliar o desenho urbano do empreendimento, a relação com o entorno, a dimensão das quadras, as aberturas para o espaço público e a rede de circulação de pedestres. Essa categoria evidência a importância de empreendimentos habitacionais que se relacionem com o entorno, com quadras de tamanhos adequados para os percursos dos pedestres, com acessibilidade entre o espaço público e espaço privado, para garantir espaços mais movimentados e seguros, e caminhos de pedestres (calçadas, passagens) com padrões de acessibilidade e qualidade.

Para a aprovação do empreendimento habitacional é necessário que os 9 indicadores recebam no mínimo a classificação aceitável, sendo que, se qualquer um dos indicadores for classificado como insuficiente o empreendimento é reprovado. Com isso é possível obter uma caracterização geral o modelo habitacional produzido pelo MCMV em Lajeado e os problemas verificados nos empreendimentos habitacionais.

Para realizar a análise por meio da ferramenta do ITDP foi necessário a coleta de dados dos empreendimentos, a utilização de imagens e mapas atuais do Google Earth e Google Maps, complementados por visitas in loco. A coleta desses dados e informações, bem como a aplicação das análises foi desenvolvida por estudantes da disciplina de Planejamento Urbano e Regional, do curso de Arquitetura e Urbanismo da UNIVATES. Os resultados, posteriormente, foram conferidos pelas autoras do presente artigo. 


\section{RESULTADOS E DISCUSSÃO}

A análise dos empreendimentos MCMV em Lajeado permite traçar um panorama geral da produção habitacional recente no município, sob a perspectiva da tipologia de condomínios de habitação multifamiliar a preços acessíveis. A Tabela 3 traz um resumo dos resultados obtidos para cada indicador - bom, aceitável ou insuficiente - e a avaliação final do empreendimento aprovado (A) ou reprovado (R).

Tabela 3 -Resultados obtidos por meio da Ferramenta de Avaliação do ITDP

\begin{tabular}{|c|c|c|c|c|c|c|c|c|c|c|}
\hline \multirow{3}{*}{ 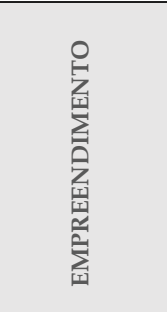 } & \multicolumn{10}{|c|}{ INDICADORES } \\
\hline & \multicolumn{2}{|c|}{ TRANSPORTE } & \multicolumn{3}{|c|}{$\begin{array}{l}\text { OFERTA DE EOUIP. } \\
\text { COMÉRCIO E SERVICCOS }\end{array}$} & \multicolumn{4}{|c|}{ DESENHO E INTEGRAÇÃO URBANA } & \multirow[b]{2}{*}{ 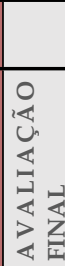 } \\
\hline & 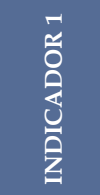 & 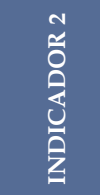 & $\begin{array}{l}m \\
\approx \\
0 \\
z \\
z \\
z \\
z \\
z\end{array}$ & 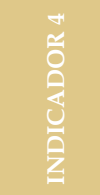 & 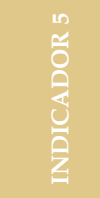 & 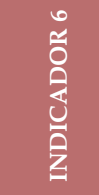 & 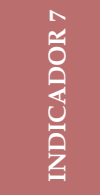 & 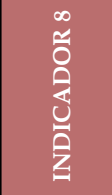 & 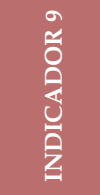 & \\
\hline $\begin{array}{l}1 \text { - Novo } \\
\text { Tempo I }\end{array}$ & BOM & INSUF & INSUF & BOM & $\mathrm{BOM}$ & ACEIT & BOM & INSUF & INSUF & $\mathbf{R}$ \\
\hline $\begin{array}{l}2 \text { - Novo } \\
\text { Tempo II } \\
\end{array}$ & BOM & INSUF & INSUF & BOM & BOM & INSUF & BOM & INSUF & INSUF & $\mathbf{R}$ \\
\hline $\begin{array}{l}\text { 3-Residencial } \\
\text { Floresta }\end{array}$ & BOM & INSUF & INSUF & ACEIT & BOM & INSUF & ACEIT & INSUF & INSUF & $\mathbf{R}$ \\
\hline $\begin{array}{l}\text { 4- Condomí- } \\
\text { nio Universi- } \\
\text { tário }\end{array}$ & $\mathrm{BOM}$ & INSUF & INSUF & BOM & BOM & INSUF & INSUF & INSUF & INSUF & $\mathbf{R}$ \\
\hline $\begin{array}{c}5 \text { - Residen- } \\
\text { cial do Parque }\end{array}$ & BOM & BOM & BOM & BOM & BOM & BOM & ACEIT & ACEIT & INSUF* & $\mathbf{R}$ \\
\hline $\begin{array}{l}6 \text { - Residen- } \\
\text { cial Terracota }\end{array}$ & INSUF & INSUF & ACEIT & INSUF & ACEIT & ACEIT & INSUF & ACEIT & INSUF & $\mathbf{R}$ \\
\hline $\begin{array}{l}\text { 7- Flores da } \\
\text { Montanha }\end{array}$ & INSUF & INSUF & ACEIT & INSUF & ACEIT & INSUF & INSUF & BOM & INSUF & $\mathbf{R}$ \\
\hline
\end{tabular}

Fonte: Elaborado pelas autoras

Observa-se que, sob o ponto de vista do transporte, há a oferta de transporte público próximo aos empreendimentos habitacionais, porém a frequência do transporte é insuficiente e o tempo de espera não é aceitável. $\mathrm{O}$ único empreendimento habitacional que apresentou bom resultado nos indicadores referentes ao transporte (indicador 1 e 2) foi o Residencial do Parque, o qual se insere na malha urbana da cidade, no bairro Centro. Próximo ao empreendimento localizam-se duas paradas de ônibus que apresentam maior disponibilidade de transporte público, com opções de itinerários e com frequência adequada. Desse modo, o empreendimento Residencial do Parque está bem conectado ao restante da cidade, permitindo que os moradores acessem diferentes destinos do município. Apesar dos outros empreendimentos não se localizarem no Centro, também deveriam dispor de opções de transporte público com frequência regular. 
Com relação aos equipamentos, comércio e serviços, constatou-se que a maioria dos empreendimentos se classificam como insuficientes em relação a presença de usos cotidianos próximo aos empreendimentos (indicador 3). As principais carências de serviços próximos aos empreendimentos habitacionais são de usos obrigatórios como creches e escolas infantis, normalmente localizados a uma distância maior do que 1.000 metros. Além disso, na maioria dos empreendimentos, verificou-se a inexistência de alguns usos complementares, como academias, farmácias e restaurantes. Os melhores resultados desse tema, oferta de equipamentos, comércio e serviços, são observados na avaliação dos usos esporádicos (indicador 5) onde todos os empreendimentos apresentaram resultado positivo, entre bom e aceitável. Devido a cidade ser de porte médio, é possível ter acesso aos usos esporádicos (Hospital, Centro Público Administrativo, Instituição de Ensino Superior e outros) em no máximo 1 hora de deslocamento por transporte público. Também nesse tema, o melhor resultado foi do empreendimento Residencial do Parque, já que localiza-se no bairro Centro, onde há grande oferta de usos cotidianos, eventuais e também acessibilidade aos usos esporádicos.

$\mathrm{Na}$ análise da categoria desenho e integração (indicadores 6-9) os empreendimentos com maiores problemas constatados são o Condomínio Universitário e o Residencial Floresta. O Condomínio Universitário localizase em uma área que não é totalmente urbanizada, apresentando áreas vazias e quadras muito grandes. Além disso, apresenta um único acesso, e apenas uma pequena parcela com contato direto entre o espaço privado do empreendimento e a área pública, de acordo com a Figura 2. Da mesma forma o Residencial Floresta não apresenta boa inserção urbana e relação com o entorno. $\mathrm{O}$ empreendimento situa-se em uma área mais periférica da cidade e distante da área central do município, na porção oeste da RS130, conforme Figura 3. Na rede de circulação de pedestres próxima aos empreendimentos foram verificados trechos sem calçada e sem arborização. 
Figura 2 - Condomínio Universitário

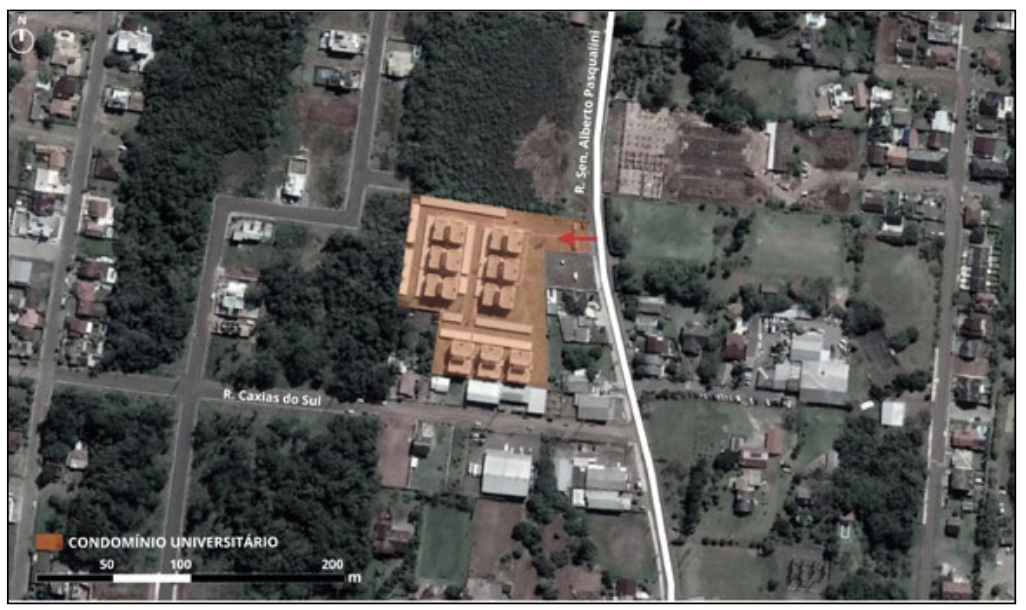

Fonte: Esquema das autoras sobre imagem do Google Earth, 2019.

Figura 3 - Residencial Floresta

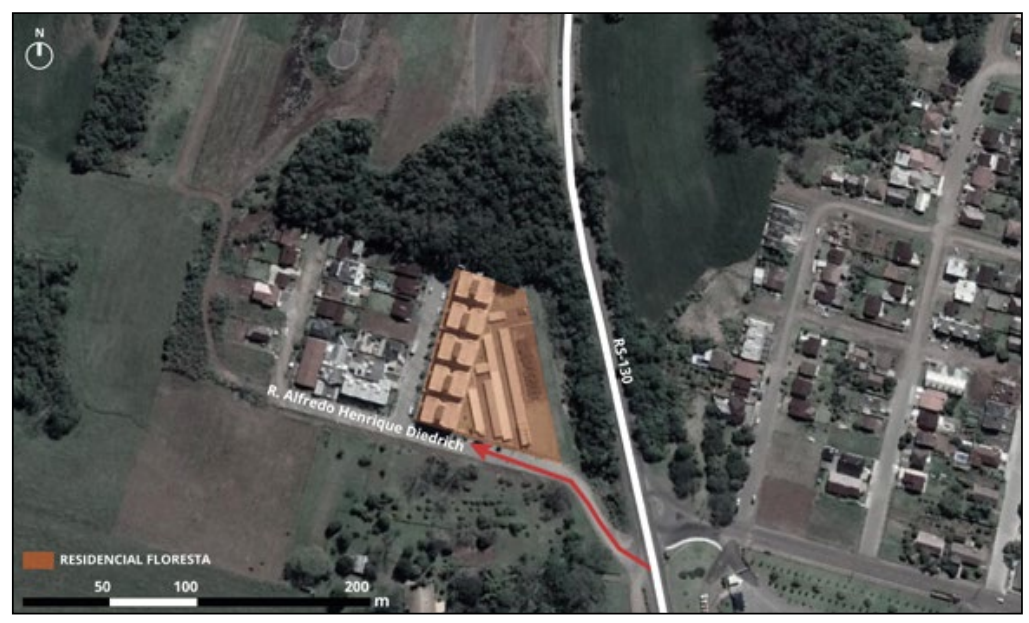

Fonte: Esquema das autoras sobre imagem do Google Earth, 2019.

Ainda no tema desenho e integração o melhor resultado verificado é do Residencial do Parque, que se insere dentro da malha urbana de Lajeado e apresenta boa relação com o entorno, tamanho de quadras aceitável e dois acessos ao empreendimento. Porém, nas proximidades do empreendimento Residencial do Parque também foram verificados problemas na rede de circulação de pedestres, a maior parte dos caminhos são pavimentados, mas existem trechos sem pavimentação, sem iluminação, sem arborização e principalmente sem acessibilidade. 
Figura 4 - R. Carlos Spohr Filho, próximo ao Residencial do Parque

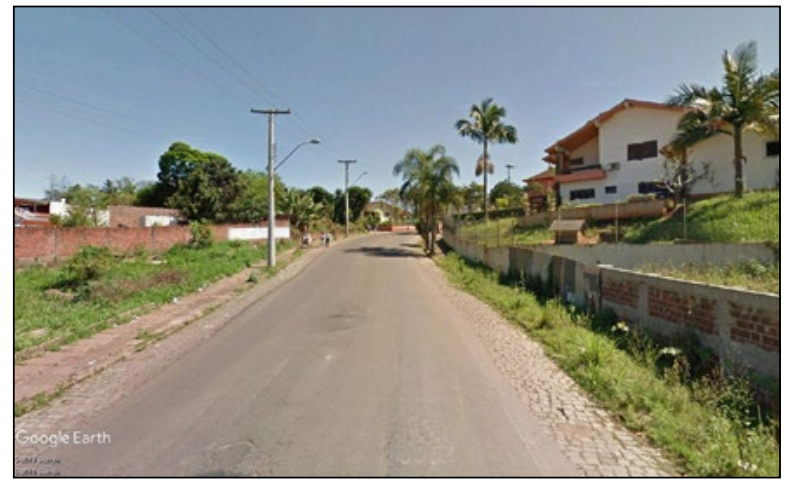

Fonte: Street View, Google Earth 2019.

Figura 5 - R. João Sebastiany, em frente ao empreendimento Flores da Montanha

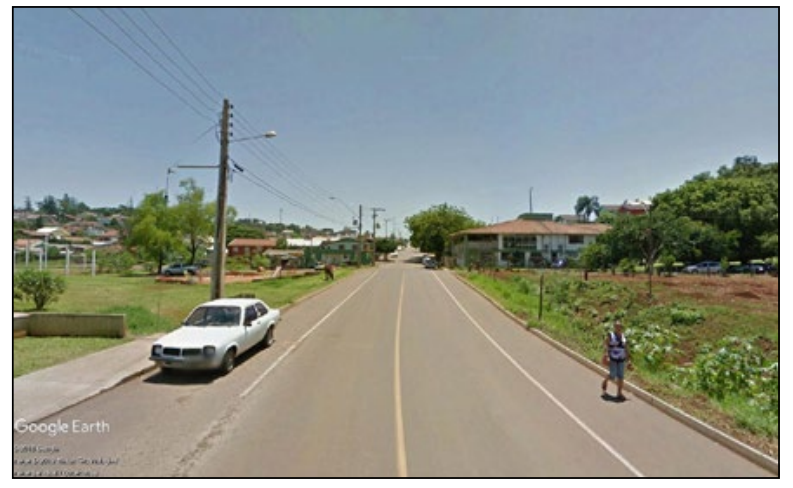

Fonte: Street View, Google Earth 2019.

Figura 6 - R. Paulo Emílio Thiesen, próximo ao Residencial Terracota

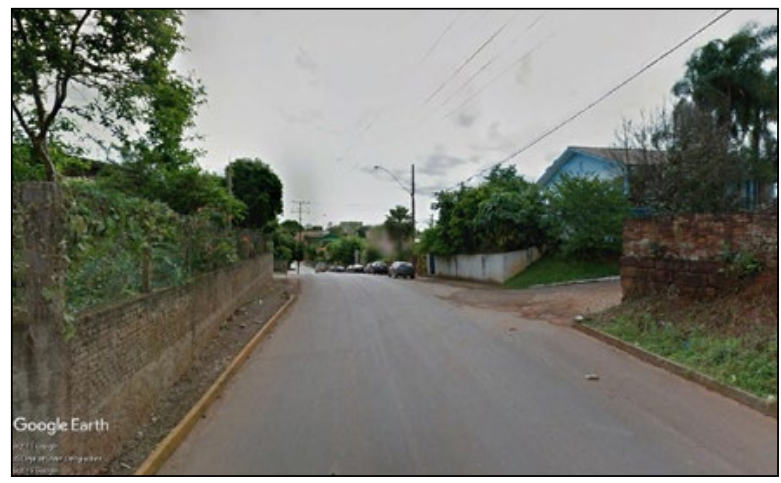

Fonte: Street View, Google Earth 2019. 
Figura 7 - R. Alfredo Henrique Diedrich, em frente ao Residencial Floresta

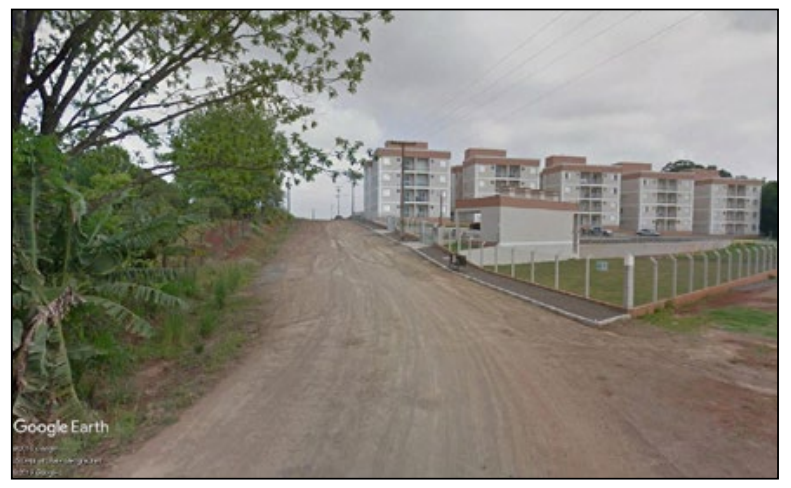

Fonte: Street View, Google Earth 2019.

Como resultado final, seguindo todos os critérios estabelecidos pela Ferramenta de Avaliação do ITDP, os 7 empreendimentos analisados foram reprovados, pois todos apresentam algum indicador com resultado insuficiente. No entanto, o Residencial do Parque apresentou resultados melhores que os outros empreendimentos, possuindo resultado insuficiente apenas no indicador 9 - que avalia a rede de circulação de pedestres. Caso esse indicador fosse relativizado, o Residencial do Parque seria aprovado. Esse indicador foi considerado insuficiente em todos os empreendimentos, o que indica que os resultados ruins nesse indicador podem ser de problemas decorrentes da falta de infraestrutura e da má qualidade do espaço público da cidade, conforme exemplificado nas Figuras 4, 5, 6 e 7. Outro problema observado, da frequência inadequada do transporte público, também parece ser advindo da falta de qualidade geral do transporte público, impactando diretamente nos empreendimentos habitacionais. A base desses problemas tem relação com o padrão de urbanização dispersa observado no município de Lajeado (LAPPE; SANTOS, 2018).

Assim, é importante a compreensão de que muitos resultados negativos encontrados nos resultados da Tabela 3 são decorrentes do próprio padrão de urbanização da cidade, e não problemas pontuais dos empreendimentos. Provavelmente a análise de outros empreendimentos habitacionais, não pertencentes ao PMCMV, também apresentariam os mesmos resultados.

\section{CONSIDERAÇÕES FINAIS}

A Ferramenta de Avaliação do ITDP fornece subsídios para a análise de empreendimentos habitacionais. No presente artigo possibilitou uma avaliação geral sobre a produção habitacional de Lajeado, mas que não traduz apenas os problemas das habitações financiadas pelo PMCMV, e sim as condições urbanísticas da cidade. Assim como Lajeado, outros municípios, especialmente 
aqueles com menos de 100.000 habitantes, padecem dos mesmos problemas de precariedade nos padrões de urbanização, infraestrutura e serviços. Tendo em vista que as prefeituras, na maior parte das cidades brasileiras, já enfrentam dificuldade de prover infraestrutura às áreas de urbanização consolidada, a implantação de conjuntos habitacionais localizados em áreas pouco urbanizadas impõe sério desafio no combate ao déficit. Conforme discutido anteriormente, sanar o déficit não é apenas uma questão quantitativa, mas sim de dar acesso à cidade, aos empregos e aos serviços básicos.

Com isso, constata-se a urgência de, não apenas em aperfeiçoar os critérios e a fiscalização da implantação dos empreendimentos do Programa MCMV, mas também de maiores investimentos na área de transportes e na melhor distribuição de equipamentos e serviços nos municípios brasileiros. Apenas dessa forma se evitará o modelo habitacional periférico e o padrão de urbanização disperso, que causam segregação e sérios prejuízos à qualidade do habitar.

\section{AGRADECIMENTOS}

As autoras agradecem aos alunos da disciplina de Planejamento Urbano e Regional, do curso de Arquitetura e Urbanismo da UNIVATES, em especial às turmas do semestre 2017-B, pelo empenho na coleta de dados e informações que subsidiaram as análises deste artigo.

\section{REFERÊNCIAS}

ANDRADE, Luciana; DEMARTINI, Juliana; CRUZ, Rogério. A banalidade do mal na arquitetura: desafios de projetos do Programa Minha Casa, Minha Vida. Revista e-metropolis, n.17, p. 52-61, jun. 2014.

BERGAMASCHI, Eliza; SILVEIRA Rogério L. L. da. Os novos produtos imobiliários residenciais e as mudanças na organização espacial da cidade de Lajeado - RS.

Geografia Ensino \& Pesquisa. v. 18, n. 3, p.7-26, out. 2014. Disponível em: <https:/ / periodicos.ufsm.br/geografia/article/view/13357>. Acesso em: 27 out. 2019.

BONDUKI, Nabil. Origens da habitação social no Brasil. Análise Social, v. XXIX, n. 127, p. 711-732, 1994.

BONDUKI, Nabil. Política habitacional e inclusão social no Brasil: revisão histórica e novas perspectivas no governo Lula. Revista Eletrônica de Arquitetura e Urbanismo, São Paulo, n.1, p.70-104, 2008. Disponível em: <http://www.usjt.br/arq.urb/ numero_01/artigo_05_180908.pdf> Acesso em: 08 out. 2019.

BRASIL. Secretaria de Avaliação, Planejamento, Energia e Loteria. Boletim mensal sobre os subsídios da União: Programa Minha Casa Minha Vida. 10. ed. Agosto de 2019. Disponível em: <http:/ / www.economia.gov.br/central-de-conteudos/ 
publicacoes/relatorios-e-boletins/2019/boletim-mensal-sobre-os-subsidios-da-uniao2013-programa-minha-casa-minha-vida-edicao-10.pdf/view >. Acesso em: 22 out. 2019.

CARDOSO, Adauto; ARAGÃO, Thêmis; ARAÚJO, Flávia. Habitação de interesse social: política ou mercado? Reflexos sobre a construção do espaço metropolitano. In: ENCONTRO NACIONAL DA ANPUR, XIV, Rio de Janeiro, 2011. Anais do XIV Encontro Nacional da ANPUR. Rio de Janeiro: ANPUR, 2011.

COMARU, Francisco. Em defesa da habitação social nas áreas centrais. Le Monde Diplomatique Brasil. p.36-37, set.2012.

FERREIRA, João S. W. Produzir casas ou construir cidades? Desafios para um novo Brasil Urbano. 1'a ed. São Paulo: FUPAM, 2012. Disponível em: < http://www.fau. usp.br/depprojeto/labhab/biblioteca/textos/ferreira_2012_produzirhab_cidades. pdf >. Acesso em: 05 out. 2019.

FREITAS, Eleusina L. H. de. Como qualificar conjuntos habitacionais populares. Brasília: Caixa Econômica Federal, 2004. 200 f. Dissertação (Mestrado) - Faculdade de Arquitetura e Urbanismo da PUC, Campinas, 2002. Disponível em: <http:/ /www.fau. usp.br/depprojeto/labhab/biblioteca/teses/freitas_mestrado_comoqualificar.pdf > Acesso em: 07 out. 2019.

IBGE - INSTITUTO BRASILEIRO DE GEOGRAFIA E ESTATÍSTICA. Censo Demográfico 2000/2010. Disponível em: <https:/ /www.ibge.gov.br>. Acesso em: 23 out. 2019.

ITDP - INSTITUTO DE POLÍTICAS DE TRANSPORTE E DESENVOLVIMENTO; LABCIDADE. Ferramenta de avaliação de inserção urbana para os empreendimentos de faixa 1 do programa Minha Casa Minha Vida. Rio de Janeiro: ITDP, 2014. Disponível em < https://www.itdp.org/2014/11/01/ferramenta-deavaliacao-de-insercao-urbana>. Acesso em 21 out. 2019.

LAPPE, Fernanda Daroit; SANTOS, Alexandre Pereira. A CIDADE DISPERSA E SUA INFRAESTRUTURA COMO CONSEQUÊNCIA: UM ESTUDO PARA A CIDADE DE LAJEADO/RS. Revista Destaques acadêmicos, Lajeado, v.10, n.4, p. 260-278, 2018. Disponível em: < http://univates.br/revistas/index.php/destaques/article/ view/2042/1459>. Acesso em: 28 out. 2019.

LEITE, Carlos; AWAD, Juliana. Cidades Sustentáveis, Cidades Inteligentes: desenvolvimento sustentável num planeta urbano. Porto Alegre: Bookman, 2012.

LIMA, Márcia A. de. A influência da dimensão, configuração e localização de conjuntos habitacionais na interação social. 2011. 269 f. Dissertação (Mestrado em Arquitetura) - Programa de Pós-graduação em Planejamento Urbano e Regional, Faculdade de Arquitetura, Universidade Federal do Rio Grande do Sul, Porto Alegre, 2011. Disponível em: < http://hdl.handle.net/10183/38945>. Acesso em: 09 out. 2019.

LIMA, Márcia A. de. Padrões espaciais de localização dos empreendimentos do Programa Minha Casa Minha Vida: impactos na qualidade da habitação social e satisfação dos moradores. 2016. 384 f. Tese (Doutorado) - Faculdade de Arquitetura, 
Programa de Pós-Graduação em Planejamento Urbano e Regional, Porto Alegre, 2016. Disponível em: <http://hdl.handle.net/10183/151375>. Acesso em: 09 out. 2019.

LINKE, Clarisse; SERRA, Bernardo; GARREFA, Fernando; ARAÚJO, Débora Cristina; VILLA, Simone Barbosa; NADALIN, Vanessa; KRAUSE, Cleandro. Inserção urbana de habitação de interesse social: um olhar sobre mobilidade cotidiana e uso do solo. Texto para Discussão, n.2176. Brasília: IPEA, 2016. Disponível em < http:/ / repositorio.ipea.gov.br/>. Acesso em 29 out. 2019.

\section{MELCHIORS, Lúcia C. AGENTES PRODUTORES DO ESPAÇO URBANO E A QUESTÃO DA HABITAÇÃO: Distribuição do Programa Minha Casa, Minha Vida no município de Gravataí/ Região Metropolitana de Porto Alegre - RS. 2014. 196 f. Dissertação (Mestrado) - Universidade Federal do Rio Grande do Sul, Faculdade de Arquitetura, Programa de Pós-Graduação em Planejamento Urbano e Regional, Porto Alegre, 2014. Disponível em: < http:/ /hdl.handle.net/10183/107512>. Acesso em: 09 out. 2019.}

\section{MINISTÉRIO DAS CIDADES; WRI. Análise de Custos Referenciais - Qualificação} da Inserção Urbana. Brasília: Ministério das Cidades, 2017. Disponível em <http:/ / www.minhacasaminhavida.gov.br/habitacao-cidades/agenda-mcmv-sustentavelsnh/61-snh-secretaria-nacional/biblioteca/5448-cadernos-minha-casa-sustentavel>. Acesso em 08 out. 2019.

MOYSÉS, Aristides; CUNHAM, Débora F.; BORGES, Elcileni de Melo; MAIA, Tule C. B. Impactos da produção habitacional contemporânea na Região Metropolitana de Goiânia: dinâmica, estratégias de mercado e a configuração de novas espacialidades e centralidades. In: CARDOSO, Adauto L. (Org). O programa Minha Casa Minha Vida e seus Efeitos Territoriais. Rio de Janeiro: Letra Capital, 2013. p. 255-278.

NETO, Vicente; FURTADO, Bernardo; KRAUSE, Cleandro. Estimativas do déficit habitacional brasileiro. Nota Técnica n.5. Brasília: IPEA, 2013. Disponível em <http:/ / www.en.ipea.gov.br/agencia/images/stories/PDFs/nota_tecnica/131125_ notatecnicadirur05.pdf>. Acesso em 08 out. 2019.

ROLNIK, R.; NAKANO, K. As armadilhas do Pacote Habitacional. Le Monde. Diplomatique. São Paulo. Março. 2009. Disponível em: <https:/ / diplomatique.org. br/as-armadilhas-do-pacote-habitacional/> . Acesso em: 08 out. 2019.

SILVA, Marlon L. da; TOURINHO, Helena L. Z. O Banco Nacional de Habitação e o Programa Minha Casa Minha Vida: duas políticas habitacionais e uma mesma lógica locacional. Cadernos Metrópole, São Paulo, v. 17, n. 34, p. 401-417, 2015. Disponível em: < http:/ / www.scielo.br/pdf/cm/v17n34/2236-9996-cm-17-34-0401.pdf>. Acesso em: 09 out. 2019.

VANNUCHI, Luanda V. B.; IACOVINI, Rodrigo F. G..; PEREIRA, Álvaro L. dos S.; MOREIRA, Fernanda A. Inserção urbana no MCMV e a efetivação do direito à moradia adequada: uma avaliação de sete empreendimentos no estado de São Paulo. In: Anais do XVI ENANPUR - Espaço, Planejamento e Insurgências. Belo Horizonte, 2015. Disponível em: <http:/ / www.labcidade.fau.usp.br/download/PDF/2015_ ANPUR_MCMV_1.pdf>. Acesso em: 08 out. 2019. 